\title{
Managing Carbon Regulatory Risk in Utility Resource Planning: Current Practices in the Western United States
}

\author{
Galen Barbose*, Ryan Wiser, Amol Phadke, Charles Goldman \\ Ernest Orlando Lawrence Berkeley National Laboratory \\ 1 Cyclotron Road, MS 90R4000 \\ Berkeley, CA 94720, USA
}

\begin{abstract}
Concerns about global climate change have substantially increased the likelihood that future policy will seek to minimize carbon dioxide emissions. As such, even today, electric utilities are making resource planning and investment decisions that consider the possible implications of these future carbon regulations. In this article, we examine the manner in which utilities assess the financial risks associated with future carbon regulations within their long-term resource plans. We base our analysis on a review of the most recent resource plans filed by fifteen electric utilities in the Western United States. Virtually all of these utilities made some effort to quantitatively evaluate the potential cost of future carbon regulations when analyzing alternate supply- and demand-side resource options for meeting customer load. Even without Federal climate regulation in the U.S., the prospect of that regulation is already having an impact on utility decision-making and resource choices. That said, the methods and assumptions used by utilities to analyze carbon regulatory risk, and the impact of that analysis on their choice of a particular resource strategy, vary considerably, revealing a number of opportunities for analytic improvement. Though our review focuses on a subset of U.S. electric utilities, this work holds implications for all electric utilities and energy policymakers who are seeking to minimize the compliance costs associated with future carbon regulations.
\end{abstract}

Key Words: electric utilities, resource planning, risk, carbon, greenhouse gas, climate change, mitigation

\section{Introduction}

Regulated electric utilities in many U.S. jurisdictions are required to prepare long-term resource plans to evaluate demand- and supply-side resource options for meeting customer load requirements over periods typically spanning ten to twenty years. ${ }^{1}$ Typically, this is done through an evaluation of various "candidate portfolios," each consisting of a different mix of supply- and demand-side resources; based on that analysis, a "preferred portfolio" of generation and efficiency investments is proposed.

Given the long development lead-time and economic lifetime of most electric infrastructure investments, utilities must evaluate the potential costs and risks of candidate portfolios over a lengthy time horizon. One long-term and potentially far-reaching financial risk currently facing

\footnotetext{
${ }^{*}$ Corresponding author. Tel.: +1510 495 2593; fax: +1510 486 6996. E-mail addresses: glbarbose@lbl.gov (G. Barbose), rhwiser@lbl.gov (R. Wiser), aaphadke@lbl.gov (A. Phadke), and cagoldman@lbl.gov (C. Goldman).

${ }^{1}$ We use the term resource plan to include what are variously referred to as integrated resource plans, least-cost plans, long-term procurement plans, default electric supply plans, and the like.
} 
the electricity industry is the uncertain cost of future carbon dioxide $\left(\mathrm{CO}_{2}\right)$ regulations. ${ }^{2}$ Notwithstanding the fact that Federal climate regulation does not yet exist in the U.S., many utilities are beginning to actively assess the potential cost of future carbon regulations within their resource plans, and are starting to evaluate options for limiting their exposure to these highly uncertain costs. Issues of environmental regulatory risk are, in fact, not new to utility planning, and a variety of authors have discussed the need for utilities to consider such risks. ${ }^{3}$ However, the risks posed by the possibility of future greenhouse gas regulations are of unprecedented scale and scope. How utilities evaluate and manage these risks may have substantial implications for generation and demand-side resource choices. Yet, with few exceptions, little effort has been made to assess how utilities (and their regulators) might best analyze and manage these risks through existing resource planning and investment processes.

As a step in this direction, we examine the treatment of carbon regulatory risk in the most recent resource plans filed by fifteen electric utilities in the Western United States (see Table 1). ${ }^{4}$ Together, these utilities account for approximately $60 \%$ of retail electricity sales in the West, and cover nine of eleven Western states. Our comparative analysis has two related elements.

First, we compare and assess utilities' approaches to addressing key analytical issues that arise when considering the risk of future carbon regulations, including:

- assumptions about the future design of carbon regulations and the cost of carbon emissions;

- the degree to which low-carbon resources and candidate portfolios are evaluated;

- the effects of carbon regulations on other aspects of the utility planning environment (e.g., effects on load growth, natural gas prices, and fossil plant retirements); and

- the manner in which uncertainty in portfolio costs associated with future carbon regulations is considered in the process of selecting a preferred resource portfolio. ${ }^{5}$

Second, we summarize the composition and carbon intensity of the preferred resource portfolios selected by the fifteen utilities in their resource plans. This component of our analysis highlights general trends and differences in the strategic direction of Western utilities, and the implications of these decisions for their exposure to carbon regulatory risk.

Though our review focuses on a subset of U.S. electric utilities, this work holds implications for all electric utilities and energy policymakers that are seeking to minimize the compliance costs

\footnotetext{
${ }^{2}$ Though we only address financial risks related to future climate change regulations, utilities also face risks associated with the physical impacts of climate change, itself (e.g., the potential effects on electricity consumption, hydro-electric generation, and cooling water availability, among others).

${ }^{3}$ Other work that has explored the implications of environmental regulatory risk for utility policy, planning, and investment decisions includes: Andrews and Govil (1996), Bokenkamp et al. (2005), Cavanagh et al. (1993), Clemmer and Freese (2006), Gardiner and Associates (2006), Johnston et al. (2006), Repetto and Henderson (2003), and Wiser et al. (2004).

${ }^{4}$ This article draws from a lengthier study conducted by Berkeley Lab (Barbose et al. 2008). Our review is limited to the resource plans filed by utilities. This work builds off of previous efforts at Berkeley Lab to evaluate Western utility resource plans, including Bolinger and Wiser (2005), which examines the treatment of renewable energy; and Hopper, Goldman, and Schlegel (2006), which examines the treatment of energy efficiency.

${ }^{5}$ Another important methodological issue, which we do not address, is utilities' assumptions about the cost and performance of different types of resources (low-carbon or otherwise); see Bolinger and Wiser (2005) for a comparison of utilities' cost and performance assumptions for various renewable electricity sources.
} 
associated with future carbon regulations. Even in areas where carbon regulations already exist, the possibility of strengthened future policies must be considered in planning decisions. As such, a major component of our effort is to develop a series of recommendations for how energy planners might better address and manage the risk of future carbon regulations.

The remainder of this article is organized as follows. We begin in Section 2 by characterizing the significance of carbon regulatory risk for electric resource economics. In the following four sections, we compare utilities' treatment of the four analytical issues itemized above, namely: their base-case and alternate assumptions about future carbon regulations and emission prices (Section 3); the extent to which they evaluated low-carbon candidate portfolios and the underlying type and quantity of low-carbon resources included in those portfolios (Section 4); the potential indirect impacts of carbon regulations that utilities considered in their portfolio analysis (Section 5); and the manner in which information about uncertainty in carbon emission costs informed utilities' selection of specific preferred resource portfolios (Section 6). In Section 7 , we describe the composition and carbon intensity of the preferred resource portfolios selected by the fifteen utilities. Last, in Section 8, we offer several concluding remarks and recommendations for utilities and energy policymakers that are seeking to minimize the costs associated with future carbon regulations.

\section{The Importance of Carbon Regulatory Risk for Utility Resource Planning}

The emergence of carbon regulatory risk as a fundamental issue for utility resource planning stems, in part, from growing consensus within the industry that carbon regulations are likely to be enacted (or become more stringent) well within the lifetime of new resource investments. In a recent poll of approximately 100 senior electricity industry executives in the U.S., for example, about half expected federal climate change legislation to be enacted by 2009, and more than $90 \%$ expected such legislation to be adopted by 2014 (GF Energy 2007). These sentiments are, no doubt, fueled by the proactive efforts of other countries to limit carbon emissions, as well as by the array of legislative proposals introduced in the U.S. Congress over the past several years and by the fact that, in the absence of federal legislation, many states have begun taking action on their own to limit greenhouse gas emissions. ${ }^{6}$

In addition to perceptions of increasing likelihood, carbon regulations represent a significant regulatory risk because of the potentially dramatic impact they could have on electric resource costs. To illustrate the potential impact of a carbon tax or cap-and-trade system on the relative cost of different electric resource options, Figure 1 translates carbon emission prices into incremental operating costs for various resource options. Overlaid on top of these cost curves are projections from the Energy Information Administration (EIA) of the $\mathrm{CO}_{2}$ emission allowance prices (EIA 2003, 2007a, and 2007b) that could occur under a range of U.S. federal legislative proposals: the McCain-Lieberman Climate Stewardship Act of 2003 (S.139), draft legislation prepared by Senator Bingaman in late 2006, and the McCain-Lieberman Climate Stewardship and Innovation Act of 2007 (S.280).

\footnotetext{
${ }^{6}$ For recent summaries of existing state and regional carbon policies throughout the U.S., see Lutsey and Sperling (2008) and Pew Center (2007).
} 
All three of these proposals would establish economy-wide cap-and-trade systems for U.S. greenhouse gas emissions, but they differ significantly in terms of the size and timing of the emission cuts and other key provisions. EIA's projection of $\mathrm{CO}_{2}$ emission prices for the 2006 Bingaman proposal corresponds to a levelized emission price of approximately $\$ 6 / \mathrm{short} \mathrm{ton}^{7}$ over the period 2010-2030, adding about \$6/MWh to the operating cost of coal-fired power generation without carbon capture and storage (CCS) and about \$3/MWh to the cost of natural gas-fired combined cycle gas turbine generation (CCGT). At the other end of the spectrum, EIA's projection of emission prices under S.139 corresponds to a levelized price of approximately $\$ 44 /$ short ton, which would add about $\$ 41 / \mathrm{MWh}$ to the operating cost of coal-fired generation without CCS, and about $\$ 18 / \mathrm{MWh}$ to the cost of a CCGT. Such a price increase could fundamentally alter the relative economics of different electric resource options.

\section{Carbon Regulations and Emission Prices Modeled in Utility Resource Plans}

The starting point in quantitatively evaluating carbon regulatory risk is to develop specific assumptions about the carbon regulations that could plausibly be implemented over the lifetime of the resource investments being considered. Given the high degree of uncertainty in the nature and timing of future carbon regulations, utilities often develop a range of alternate assumptions to evaluate through scenario analyses. In this section, we describe the carbon regulations that utilities in our sample posited when estimating the cost of alternate candidate portfolios, with particular attention to their projections of potential carbon emission prices under a carbon tax or cap-and-trade system.

\subsection{Utility projections of carbon emission prices}

With only one exception, all of the utilities in our review - in many cases following a regulatory mandate $^{8}$ - incorporated the possibility of future carbon regulations into their analysis of different resource options, either as part of their base-case analysis scenario, in alternate scenarios, or both. ${ }^{9}$ In California and Oregon, the state's electricity regulators (public utility commissions, or PUCs) specified the carbon emission prices that investor-owned utilities were required to incorporate in their resource planning analyses. ${ }^{10}$ Where state PUCs have not

\footnotetext{
${ }^{7} 1$ short ton $=0.907$ metric tons

${ }^{8}$ Resource planning rules in California, Oregon, Montana, and Washington require investor-owned utilities to include carbon emission costs in their resource planning analysis and/or to evaluate risks associated with future carbon emission regulations. Resource planning rules in Nevada and Utah require utilities to consider environmental externalities, which can function as a proxy for regulatory compliance costs, but do not specifically mention carbon emission externalities or carbon regulatory costs.

${ }^{9}$ Utilities generally specified few details about the carbon tax or cap-and-trade modeled in their resource plan other than a projection of carbon emission prices, and in some cases referred to the two types of policies interchangeably. From the perspective of evaluating future resource investments, carbon taxes and cap-and-trade systems are functionally similar, in that both establish a standardized price per unit of emissions, although prices may be less volatile under a carbon tax (Parry and Pizer 2007). Other important differences exist between the two policies, as well as among cap-and-trade programs (e.g., allowance allocation); however, most of these differences relate primarily to distribution effects and are therefore largely immaterial from the specific perspective of a utility evaluating future resource investments. One design issue that is relevant to utility resource investment decisions, though, is whether utilities are freely allocated allowances for new fossil-fuel fired power plants.

${ }^{10}$ The California PUC requires the state's utilities to use an emission price of $\$ 8$ per ton of $\mathrm{CO}_{2}$ (nominal) starting in 2004, escalating at 5\% per year. The Oregon PUC requires the state's utilities to conduct scenario analyses with carbon prices of $\$ 0, \$ 10, \$ 25$, and $\$ 40$ per ton (1990\$) but does not specify the timing of those prices.
} 
provided specific guidance or requirements regarding carbon price assumptions, utilities have often relied on analyses of recent federal legislative proposals. For example, six utilities assumed carbon emission prices equal to the safety-valve price initially recommended by the National Commission on Energy Policy (NCEP 2004).

In Figure 2, we compare utilities' base-case and alternative $\mathrm{CO}_{2}$ price projections in terms of the levelized price over the period 2010-2030. These levelized prices capture differences in the overall magnitude of utilities' price projections, as well as differences in their assumptions about when carbon regulations would come into effect. We benchmark these assumptions against EIA's projections of carbon emission allowance prices under the three federal policy proposals identified previously: the original 2003 McCain-Lieberman bill (S.139), draft legislation prepared by Senator Bingaman in late-2006, and the 2007 McCain-Lieberman bill (S.280). To capture a wider set of potential policies and modeling methods and assumptions, we also show the low-, mid-, and high-range $\mathrm{CO}_{2}$ price projections developed by Synapse Energy Economics (Johnston et al, 2006). Synapse developed these projections, in part, by synthesizing the results of eleven modeling studies of five separate federal policy proposals (all issued prior to 2006).

Eleven of the fifteen utilities in our sample included carbon regulatory costs in their base-case portfolio analysis, with levelized carbon emission price projections ranging from $\$ 4$ to $\$ 20$ per short ton of $\mathrm{CO}_{2}$ (2007\$). As shown in Figure 2, many of these utilities' base-case carbon price assumptions are near the low end relative to the benchmarks provided in the figure. It would therefore appear that many utilities, especially those with no carbon regulation in their base-case analysis, may be underestimating the "most likely" cost of carbon emissions. ${ }^{11}$

Given the inherently speculative nature of projecting future policy outcomes, it is particularly important for resource planners to model candidate portfolio costs under a broad range of potential carbon emission prices. Eleven of the utilities in our review conducted scenario analyses to evaluate portfolio costs under alternate carbon price projections to their base-case (including three of the four utilities that assumed no carbon regulations in their base-case). Most of these utilities evaluated scenarios with levelized carbon prices of \$30/ton or greater, consistent with a relatively aggressive carbon policy. However, several utilities (Avista, Nevada Power, and Sierra Pacific) examined a more-limited range of carbon price scenarios, and four utilities (LADWP, PG\&E, SCE, and SDG\&E) examined no alternate carbon price scenarios. These utilities therefore had limited ability to assess the exposure of their candidate portfolios to carbon regulatory risk.

\subsection{Other types of carbon regulations considered}

Future carbon regulations could take various forms other than a federal carbon tax or cap-andtrade system, such as generator emission performance standards or technology-specific requirements (e.g., that all new coal-fired generation come equipped with carbon capture capabilities). Two Western states, California and Washington, have already established emission performance standards for electric power generation that effectively prohibit the states' utilities

\footnotetext{
${ }^{11}$ This judgment is further supported by the fact that the 2007 Bingaman-Warner bill, which effectively supplanted the 2006 draft Bingaman proposal analyzed by EIA, has a safety-valve price of \$12/metric ton, rather than the \$7/ton safety-valve price in earlier proposals.
} 
from building or signing new long-term contracts with coal-fired power plants lacking CCS, and Montana adopted a more limited standard that applies only to new, utility-owned or leased coalfired power plants. Montana, Oregon, and Washington also require that new power plants mitigate a portion of their projected carbon emissions.

Utilities in states with existing emission performance standards and/or mitigation requirements all accounted for these regulations within their resource plans (provided that the regulations were in place at the time that the resource plan was prepared). In addition, several utilities considered expansions to existing state carbon regulations. Specifically, PacifiCorp considered a scenario in which an emission performance standard similar to the one already adopted in California and Washington is implemented throughout the utility's six-state service territory. PGE, meanwhile, assumed that Oregon's existing carbon emission mitigation standard for new baseload power plants would apply to coal-fired baseload generation (not just natural gas-fired generation, as is currently the case).

Finally, notwithstanding the fact that a number of utilities considered some state-level carbon policies in their analysis, it is interesting to note that no utilities in our sample considered emission prices based specifically on existing state greenhouse gas emission reduction goals, despite the fact that these may (arguably) be a better indicator of the carbon regulatory regime faced by utilities in the near-term than is federal policy. ${ }^{12}$

\section{Consideration of Low-Carbon Resource Options and Portfolios}

A critical aspect of managing carbon regulatory risks is evaluating options for hedging those risks. At present, the primary means by which utilities in the U.S. can hedge carbon regulatory risks is by focusing future resource development on low-carbon resources. Standard practice in utility resource planning is to construct multiple candidate resource portfolios, each composed of different types and quantities of various resource options, and then estimate the cost of each candidate portfolio (often under a range of alternate assumptions about future conditions), in order to reach a decision about a single "preferred” resource strategy. A utility's ability to fully assess the cost and value of mitigating its exposure to carbon regulation risk is therefore contingent upon its consideration of a diverse array of low-carbon resources and candidate resource portfolios.

To gauge the extent to which utilities in our sample evaluated options for hedging carbon regulatory risk, we describe the carbon intensity of the candidate portfolios evaluated by each utility, in terms of their composite $\mathrm{CO}_{2}$ emission rates (see Figure 3). We calculated the composite emission rate of each candidate portfolio by averaging the $\mathrm{CO}_{2}$ emission rates of all new supply- and demand-side resources in the portfolio, weighted by their expected annual energy production (or energy savings in the case of energy efficiency) in the last year of the utility's planning period. To maintain consistency across utilities, we excluded from this calculation any contract renewals projected to occur over the planning period as well as generic

\footnotetext{
${ }^{12}$ Seven Western states have established statewide greenhouse gas emission reduction goals, and most have joined with the Canadian provinces of British Columbia and Manitoba to form the Western Climate Initiative (WCI), which is working to develop a regional cap-and-trade system and/or other market-based mechanisms to reduce the states' and provinces' combined emissions to 15\% below 2005 levels by 2020 (WCI 2007).
} 
short/medium-term market purchases. The calculated composite emission rates therefore specifically reflect the new, physical supply- and demand-side resources in each candidate portfolio. For reference, Figure 3 also shows the $\mathrm{CO}_{2}$ emission rates of combined cycle natural gas and sub-critical pulverized coal generation, representing the bookend emission rates for conventional fossil-fuel generation technologies.

Almost all of the utilities in our sample constructed at least one candidate portfolio with a composite emission rate substantially less than a CCGT (i.e., $<400 \mathrm{lbs} \mathrm{CO}_{2} / \mathrm{MWh}$ ), suggesting that most utilities did consider a good range of carbon regulation mitigation options. The only exceptions are Nevada Power, Sierra Pacific, and Tri-State, as these utilities evaluated candidate portfolios that, in almost all cases, contained significant quantities of conventional pulverized coal (without CCS) and, unlike the other utilities in our sample, did not evaluate candidate portfolios consisting primarily of energy efficiency, renewables, or other low-carbon options.

In most cases, utilities developed low-carbon candidate portfolios by first specifying aggressive energy efficiency savings targets. Nine of the fifteen utilities (Avista, LADWP, NorthWestern, PG\&E, PGE, PSE, SCE, SDG\&E, and Seattle City Light) included their estimate of the "maximum achievable" energy efficiency program savings in all candidate portfolios. This represents the portion of the total economic (cost-effective) potential that could be obtained through utility-funded energy efficiency programs in which the utility covers $100 \%$ of the incremental cost of more-efficient equipment. ${ }^{13}$ Not surprisingly, these utilities' candidate portfolios generally contained much greater levels of energy efficiency than the other utilities in our sample. Specifically, among the nine utilities whose candidate portfolios included the maximum achievable potential, energy efficiency program savings represented as much as $18 \%$ to $50 \%$ of all new energy resources in the portfolio. In comparison, the maximum contribution from energy efficiency in the other six utilities' candidate portfolios ranged from just $6 \%$ to $17 \%$ of all new energy resources.

Most utilities also evaluated candidate portfolios with a large contribution from new renewable electricity. The only exceptions were Nevada Power, Sierra Pacific, and Tri-State, which evaluated candidate portfolios with renewables representing no more than $12 \%$ of new supplyside energy resources. All other utilities constructed at least one candidate portfolio with renewables representing at least $50 \%$ of new supply-side energy resources, and three utilities (Avista, PacifiCorp, and Seattle City Light) evaluated candidate portfolios in which renewables represented $100 \%$ of all new supply-side resources. Wind power was generally identified as the renewable resource most-likely to contribute significantly to the resource supply of these candidate portfolios, though other renewable sources were also frequently included. Many of the utilities in our sample are subject to state renewables portfolio standards (RPS), which require utilities to obtain specific quantities of renewable energy, thereby setting a floor on the amount of renewables considered in resource plans. Nonetheless, almost all of these utilities (the exceptions being Nevada Power and Sierra Pacific) evaluated candidate portfolios containing greater levels of renewables than strictly required for RPS compliance.

\footnotetext{
${ }^{13}$ Maximum achievable potential is less than the full cost-effective potential due to factors including, but not limited to: (a) stock turnover rates, (b) non-economic barriers to energy efficiency adoption, and (c) naturally-occurring improvements in energy efficiency. For further discussion of the concept of maximum achievable potential as used in energy efficiency potential studies, see Rufo and Coito (2002) and National Action Plan (2007).
} 
Interestingly, compared to energy efficiency and renewable energy, other types of low-carbon resources played a relatively limited role in utilities' construction of low-carbon candidate portfolios. Despite increased attention to CCS and nuclear generation in mitigating carbon emissions, Western utilities do not expect to rely on these sources to any significant extent in the period covered by their resource plans. Only two utilities (Idaho Power and PSCo) evaluated candidate portfolios with new nuclear generation, for example, signaling continuing concern about the cost and/or public acceptance of constructing new nuclear power plants. Six utilities (Idaho Power, NorthWestern, PacifiCorp, PGE, PSCo, and PSE) evaluated candidate portfolios containing IGCC with CCS, with maximum portfolio contributions ranging from approximately $10 \%$ to $75 \%$ of all supply-side energy resources in the portfolio but, as shown later, these resources were rarely selected for the preferred portfolio. To summarize, energy efficiency and renewable energy are the dominant low-carbon strategies currently being considered by utilities in the Western U.S., although some utilities are beginning to evaluate nuclear and CCS as lowcarbon resource options.

\section{Accounting for Indirect Impacts of Carbon Regulations in Resource Planning}

Within the context of utility resource planning, the most direct effect of future carbon regulations is to increase the projected operating cost of carbon-emitting resources in the utility's candidate portfolios. However, there are a number of potential indirect impacts of carbon regulations that are somewhat less recognized, which may also be important for utilities to incorporate into their resource planning analysis.

Table 2 lists some of these potential indirect energy market impacts, and identifies whether or not utilities in our sample included these impacts in their portfolio analyses. The results suggest that utility resource planners are only beginning to acknowledge and evaluate many of these potentially significant effects, and that substantial work may be needed to assess how best to incorporate these effects into energy planning and investment decisions.

\subsection{Electricity market prices}

Analyses of carbon policy proposals typically project that carbon regulations would lead to an increase in wholesale electricity market prices. Capturing this effect is critical to utility resource planning for at least two reasons. First, different candidate portfolios generally entail different levels of exposure to wholesale market prices; ignoring the impact of carbon regulations on regional electricity market prices could therefore create a bias toward portfolios with a heavier reliance on market purchases. Second, wholesale electricity market prices are often a key input to deriving the avoided costs from energy efficiency investments. Accounting for the effect of carbon regulations on wholesale electricity prices is therefore critical to properly valuing energy efficiency cost-effectiveness and market potential in carbon-regulation scenarios.

Carbon regulations could impact regional electricity market prices through a variety of mechanisms, the most immediate being to add an emission cost to the marginal cost of 
generators throughout the region, thereby raising market prices. ${ }^{14}$ A utility's ability to account for this particular effect depends on how it develops its electricity price forecast. Several utilities in our study used regional production cost models to develop unique electricity market price forecasts for each scenario, with the particular carbon price projection for that scenario input into the simulation model. Other utilities developed their electricity price forecasts from projections of marginal heat rates for nearby trading hubs, which they translated into electricity price projections based on fuel price and carbon price forecasts. This approach is somewhat cruder than the production cost model approach, as it does not allow the utility to account for potential changes in regional dispatch order as a result of differences in the marginal emission rate of generation resources in the region. This impact could be particularly critical at carbon prices high enough to raise the operating cost of pulverized coal-fired generation to above that of a CCGT.

\subsection{Natural gas commodity prices}

Natural gas demand and, correspondingly, natural gas commodity prices may increase or decrease under carbon regulations, depending on the cost and availability of other low-carbon alternatives to coal-fired generation. ${ }^{15}$ A change in natural gas prices induced by carbon regulations is relevant to utility resource planning by (1) increasing/decreasing the expected cost of natural gas-fired generation included in the utility's candidate portfolios, and (2) increasing/decreasing electricity market prices throughout the region to the extent that gas-fired generation is the marginal generation resource. These impacts could conceivably be of the same order of magnitude as the direct emission costs associated with carbon regulations. ${ }^{16}$

Every utility in our sample evaluated candidate portfolio costs under multiple gas price forecasts; however, only four utilities explicitly linked gas prices and carbon prices for the purposes of developing electricity market price projections and modeling the cost of candidate portfolios. Three of these utilities (PSCo, PSE, and Seattle City Light) simply used their "high gas price" forecasts in their "high carbon price" scenario, although their high gas price projections were not developed based on any specific assumptions about future carbon emission prices. PacifiCorp, in contrast, commissioned an outside consultant to develop separate natural gas price forecasts specific to each of its carbon tax and cap-and-trade scenarios. None of the other utilities made any systematic link between their carbon price and natural gas price assumptions.

\footnotetext{
${ }^{14}$ Carbon regulations may also impact electricity prices (over the longer term) due to effects on fuel prices, load growth, generation retirements and additions, and transmission expansion. We discuss some of these impacts below. ${ }^{15}$ For example, under the 2007 McCain-Lieberman proposal, EIA projects that wellhead natural gas prices in 2030 would be between $5 \%$ lower and $18 \%$ higher than in the reference case, depending on assumptions about the availability of new nuclear generation, CCS, liquefied natural gas (LNG) imports, and biomass (EIA 2007b, 2007c).

${ }^{16}$ For example, a $\$ 1.00 / \mathrm{MMBtu}$ increase in the delivered price of natural gas to electric generation (about $13 \%$ of the current price) would raise the fuel cost of a CCGT by about $\$ 7 / \mathrm{MWh}$, which is comparable to the direct carbon emission cost of a CCGT with a \$20/ton carbon tax.
} 


\subsection{Load growth}

An increase in retail electricity prices associated with carbon regulations may slow load growth (distinct from the effects of energy efficiency programs). ${ }^{17}$ This dynamic is relevant to utility resource planning, first and foremost, by reducing the utility's own resource needs. Although virtually all of the utilities in our sample developed low load growth projections, only two utilities (PSE and PSCo) explicitly linked high carbon prices to low load growth within their analysis. Also relevant to utility resource planning is any effect that carbon regulations would have on load growth throughout the region, given the potential impacts of this growth on electricity market prices. Three utilities (Avista, PSE, and Seattle City Light) accounted for this potential dynamic, by assuming reduced load growth throughout the region within their simulation models used to develop electricity price projections for carbon regulation scenarios.

\subsection{Accelerated coal plant retirements}

Carbon regulations could affect the timing of generation retirements in a number of ways, the most significant of which may be to accelerate the retirement of existing coal plants. ${ }^{18}$ Such a dynamic has two-fold significance for utility resource planning. First, early retirement of a utility's own coal-fired generation will increase the size of its future resource deficit, and therefore increase its incremental resource need. Eleven of the fifteen utilities in our sample own or have long-term contracts with coal-fired generation. However, only two utilities, PGE and PSCo, conducted analyses within their resource plan to explicitly examine whether carbon regulations would justify the early retirement of their own coal-fired generation.

Second, coal-plant retirements at a regional level could affect electricity market prices, as a result of associated changes in generation dispatch order and, over the longer-term, new generation investment. A utility's ability to account for the effect of regional coal-plant retirements on electricity market prices depends, in part, on how the utility develops its electricity price forecasts. Four of the utilities in our sample (Avista, PacifiCorp, PGE, and PSE) use regional capacity expansion models linked to production cost models to project electricity market prices. In principle, this type of modeling could be used to simulate the effect of carbon regulations on regional generation retirements, and the corresponding impact on electricity market prices. However, most of these utilities' resource plans to do not provide sufficient information to determine whether their modeling accounted for this potential dynamic. The only exception is PGE, which specifically indicated that the electricity market simulation did not allow generation retirements prior to the end of each plant's original book life.

\footnotetext{
${ }^{17}$ For example, EIA projects that, compared to the respective reference cases, load growth in the Western U.S. would be 30\% lower under S.139, 26\% lower under S.280, and 5\% lower under the 2006 Bingaman proposal (EIA 2003, 2007a, and 2007b). Note, though, that these projections capture the combined effects of customer price elasticity and increased energy efficiency program activity. Also, carbon regulations could lead to increased use of plug-in hybrid electric vehicles, and to electrification of heating and cooling, both of which would tend to increase load growth.

${ }^{18}$ Estimates of the size of this effect vary significantly. For example, EIA's analysis of the original McCainLieberman climate legislation projects that almost 25\% of all coal-fired generation in the West would be retired by 2025, compared to essentially none in the reference case (EIA 2003). In contrast, EIA's analysis of the 2007 McCain-Lieberman bill projects that only 4\% of coal capacity in the West would be retired by 2030, and its analysis of the 2006 Bingaman proposal projects no such retirements (EIA 2007a, 2007b).
} 


\subsection{Other indirect impacts}

In addition to the particular effects discussed above, carbon regulations could have a multitude of other indirect impacts on regional energy markets that may be important for energy planners to consider, including:

- Allowance prices for other capped air pollutants, resulting from a reduction in traditional coal-fired power generation and correspondingly reduced demand and prices for criteria air pollutant (e.g., $\mathrm{SO}_{2}$ ) emission allowances;

- Regional generation expansion, as utilities shift their capacity expansion efforts towards low-carbon generation, which could, in turn, affect electricity market prices;

- Regional transmission expansion, as utilities construct new transmission into regions rich in low-carbon resources, which could enable broader access to these resources by other utilities;

- Availability of federal incentives, if legislators viewed existing financial incentives for lowcarbon resources as duplicative, possibly resulting in an accelerated reduction or discontinuation of those incentives;

- Capital costs and technology development associated with rapidly increasing demand for commercially-available low-carbon resources (e.g., wind) and/or accelerated "learning curve” effects for emerging low-carbon resources (e.g., concentrating solar or CCS).

\section{Incorporating Carbon Cost Uncertainty into Portfolio Selection}

\subsection{Portfolio selection under uncertainty}

Utility resource plans typically culminate by identifying a single, preferred portfolio. The process of selecting a preferred portfolio invariably involves a comparison of candidate portfolios' expected costs under base-case assumptions. Many utilities also select their preferred portfolio based upon some comparison of the uncertainty in costs of their candidate portfolios. The overall uncertainty in the cost of a candidate portfolio is the net effect of uncertainties in numerous underlying input variables. Uncertainty in some input variables (e.g., annual rainfall, summer peak temperatures, natural gas price volatility) can be defined probabilistically based on historical data. In these cases, utilities’ often use Monte Carlo methods to derive a single stochastic risk measure for each candidate portfolio, to express its overall uncertainty in cost associated with all probabilistically-defined input parameters. ${ }^{19}$ Some utilities then employ specialized modeling tools to identify the efficient frontier, defined as the set of portfolios with the lowest theoretical stochastic risk for a given expected cost (and vice-versa). ${ }^{20}$

Uncertainty in input variables for which historical data do not exist - such as carbon emission prices - is less amenable to probabilistic definition and stochastic modeling. Cost uncertainty associated with these types of variables is therefore often assessed by calculating candidate portfolio costs across a discrete number of alternate scenarios (i.e., scenario analysis rather than

\footnotetext{
${ }^{19}$ See Bolinger and Wiser (2005) for a description and discussion of stochastic risk measures used in recent utility resource plans.

${ }^{20}$ The efficient frontier concept derives from portfolio theory and was first developed by Markowitz (1952).
} 
stochastic Monte Carlo analysis). When combined with stochastic risk analysis, scenario analysis can then yield a family of efficient frontiers as illustrated in Figure 4.

Regardless of whether or not it is combined with stochastic analysis, though, scenario analysis simply yields a range of portfolio costs across multiple sets of assumptions and does not produce a precisely-defined measure of uncertainty in portfolio cost. Utilities therefore face a significant challenge in incorporating cost uncertainty associated with future carbon regulations into their preferred portfolio selection process. On the one hand, the magnitude of the uncertainty and implications for the relative economics of competing candidate portfolios are likely to be quite large. However, there is not yet an established analytic and decision-making framework to meaningfully translate information about variation in portfolio costs across multiple carbon price scenarios into the selection of a single preferred portfolio. Furthermore, utilities must ultimately make some tradeoff between the twin objectives of minimizing expected portfolio costs and minimizing uncertainty in portfolio costs and, thus far at least, relatively little effort has been placed on how best to make such tradeoffs (e.g., by assessing the risk preferences of ratepayers).

\subsection{Approaches to accounting for carbon cost uncertainty}

Perhaps as a reflection of the challenges described above, many utilities in our study appear to have not explicitly incorporated information about variation in portfolio costs across carbon price scenarios into their choice of a preferred resource portfolio. Eleven utilities evaluated candidate portfolio costs under multiple carbon price projections, and thus were able to show how candidate portfolio costs varied across carbon regulation assumptions. We reviewed the text of these utilities' resource plans to determine how, if at all, this information was used to inform the selection of the preferred portfolio. Six of these eleven utilities (Nevada Power, PGE, PSCo, Seattle City Light, Sierra Pacific, and Tri-State) made no reference to the results of their carbon scenario analysis when explaining their rationale for selecting a preferred portfolio; it is unclear what, if any, role that scenario analysis may have had in their portfolio selection processes. ${ }^{21}$

The other five utilities that evaluated portfolio costs under multiple carbon price projections did rely, to some degree, on the results from that uncertainty analysis when selecting a preferred portfolio. Although their methods differed substantially, we generalize from their approaches to identify three types of strategies that resource planners could consider for incorporating information about carbon cost uncertainty into their portfolio selection process (recognizing that other approaches may also be available):

Integrated risk metrics. Avista included carbon emission prices as a random variable in its stochastic analysis, by stipulating probabilities for a set of alternate carbon price projections and allowing its model to select a different price projection in each iteration of the Monte Carlo analysis. Each candidate portfolio's exposure to uncertainty in carbon costs was therefore captured in its overall stochastic risk metric (in Avista's case, the portfolio's standard deviation in total operating costs). Idaho Power and NorthWestern also assigned probabilities to each of their carbon price projections. Idaho Power used these probabilities to develop a "risk adder" for each candidate portfolio, while NorthWestern used the probabilities to compute a risk-adjusted

\footnotetext{
${ }^{21}$ In part, this is symptomatic of the more general tendency of utility resource plans to provide only cursory and vague explanations of the rationale for choosing a particular preferred portfolio.
} 
cost for its candidate portfolios. The risk metric approaches used by these three utilities have some advantages by creating a common numerical measure by which all portfolios can be compared, and by allowing uncertainty in carbon regulatory costs to be integrated with other uncertainties into a single metric, rather than addressing individual risks in a piecemeal fashion. However, these types of approaches are not without limitations. One potential pitfall is that they may lead to a false sense of precision in the resulting risk metric, given the subjective and highly uncertain underlying assumptions about the probability of each carbon price projection. Depending on the structure of the analysis, it may then be difficult for stakeholders to determine how altering these critical assumptions would affect the results.

Threshold analysis. PSE identified the threshold probability of its high carbon price scenario occurring such that its two finalist candidate portfolios would have the same expected cost, and then chose its preferred portfolio based on its judgment of whether the actual probability of a high carbon price scenario was higher or lower than that threshold value. As a more limited example, PacifiCorp conducted a stand-alone "break-even” analysis, separate from its overall portfolio analysis, to identify the carbon price at which its capacity expansion model would choose a CCGT rather than a coal-plant. An advantage of these types of threshold analyses is that they place the subjective judgment at the center of the decision-making process, rather than burying those assumptions deep in the analysis. That said, simply identifying the threshold says nothing about the magnitude of the potential upside and downside risks of each portfolio.

Robustness testing. PacifiCorp used a capacity expansion model to identify the least-cost portfolios under a range of carbon price scenarios, and found that the capacity expansion model always selected particular types of resources. PacifiCorp therefore concluded that these resources were resilient to carbon cost uncertainty and included them in subsequent capacity expansion model runs conducted to select the remaining resources for its preferred portfolio. Though not identical, this approach bears certain similarities to "robust methods" used in other policy arenas when conditions of deep uncertainty exist, which seek to identify strategies that minimize regret across the range of uncertainties and that maintain the ability to adapt to changing circumstances (see Lempert et al., 2006).

One overarching issue remains regardless of the approach used to account for uncertainty in carbon regulation costs. Ultimately, some tradeoff is likely to be required between minimizing expected cost and minimizing risks (e.g., uncertainty in cost). However, most utilities did not identify the criteria used to make this tradeoff, and those that did identify specific criteria (e.g., by assigning numerical weights to expected portfolio cost and portfolio risk), provided little or no explanation of the underlying rationale for the criteria used. As suggested by Bolinger and Wiser (2005), to the extent that ratepayers bear the risks associated with future carbon emission costs, the tradeoff between expected portfolio cost and portfolio risk would ideally be based on the risk preferences of ratepayers. More research is necessary, however, to identify these preferences.

\section{The Carbon Intensity of Utilities’ Preferred Resource Portfolios}

Though generally not a binding, long-term commitment, the preferred resource portfolios identified in utility resource plans nevertheless provide perhaps the best public indication of their current long-term resource strategies. In this section, we summarize the preferred resource 
portfolios selected by the fifteen utilities in our sample in order to highlight general trends and differences in the strategic direction of Western utilities, and the implications for these utilities' exposure to carbon regulatory risk. As shown here, despite the fact that federal global climate regulation does not yet exist in the U.S., the prospect of such regulation - along with an array of existing state policies directed at mitigating climate change and supporting energy efficiency and renewables - does appear to be affecting utilities’ resource choices.

Figure 5 summarizes the composition and carbon intensity of each utility's preferred portfolio, based on expected energy generation/savings in the last year of the utility's portfolio construction period (listed in Table 1). We exclude from the figure existing generation and new generation already under development/under contract at the time of the resource plan, future contract renewals, and future short/medium-term market purchases. Figure 5 instead focuses specifically on new, physical supply- and demand-side resources in each utility's preferred portfolio, and shows the carbon intensity of each utility's preferred portfolio in terms of its composite emission rate (as defined in Section 4). We present both the "Gross Emission Rate", which reflects the new resources, and the "Net Emission Rate", which also accounts for reduced emissions from planned generation retirements.

A number of high-level findings emerge from this summary:

Energy efficiency and renewable generation are the dominant low-carbon resources in utilities' preferred portfolios. All fifteen utilities selected a preferred portfolio that included expanded utility-funded energy efficiency programs and new renewable generation. In fact, half of the utilities in our sample selected portfolios in which energy efficiency and renewable energy together constitute 50\% or more of new energy resources in the portfolio. Only three utilities (Sierra Pacific, Nevada Power, and Tri-State) selected preferred portfolios in which either energy efficiency or renewables constitute less than $10 \%$ of all new resources. Also of note is that all utilities with an RPS, except for LADWP, Nevada Power, NorthWestern, and Sierra Pacific, included more renewables in their preferred portfolios than strictly required for RPS compliance.

Other types of low-carbon resources - most notably, nuclear power and CCS - play a limited role in utilities' preferred portfolios. Despite stated interest, few utilities have found that nuclear or CCS are ready for prime time during their upcoming planning period. The two utilities that evaluated candidate portfolios with new nuclear power, Idaho Power and PSCo, both included it in their preferred portfolios, although new nuclear power appears in PSCo's preferred portfolio only after the period characterized in the figure (2008-2020). ${ }^{22}$ Of the six utilities that included IGCC with CCS in their candidate portfolios, PSCo is also the only utility to include this resource in its preferred portfolio. Finally, three utilities (Idaho Power, PacifiCorp, and PG\&E) selected preferred portfolios with relatively small amounts of new combined heat and power (CHP) generation.

Natural gas is a common, although not universal, element in utilities' preferred portfolios, while utilities in inland states are continuing to pursue new coal without CCS. After energy

\footnotetext{
${ }^{22}$ PSCo constructed the supply-side of its candidate portfolios out through 2046, but identified demand-side targets only through 2020; thus, in describing its preferred resource portfolio, we focus on the period ending in 2020. Nuclear resources are added to the preferred portfolio beginning in 2022.
} 
efficiency and renewable energy, natural gas-fired generation represents the next most-common resource within the utilities' preferred portfolios. Twelve utilities' preferred portfolios include gas-fired generation, in most cases constituting at least $20 \%$ of the total portfolio and, for several utilities, upwards of $60 \%$. Meanwhile, five of the eight utilities serving inland states in the Western U.S. selected preferred portfolios containing new pulverized coal generation without CCS. Of these five, Tri-State's portfolio is the most heavily-reliant on new coal, representing 93\% of new supply- and demand-side energy resources. The four other utilities selected preferred portfolios in which new pulverized coal constitutes between $20 \%$ and $40 \%$ of the new resources. None of the seven utilities with service territories in California, Oregon, or Washington selected portfolios containing new coal without CCS, reflecting the fact that utilities in California and Washington are subject to carbon emission performance standards that effectively preclude the utilities from constructing or signing new contracts for coal-fired generation without CCS.

Retirement of existing coal-fired generation remains limited. Although not shown explicitly in Figure 5, three utilities (Nevada Power, PSCo, and Sierra Pacific) plan to retire existing coalfired generation (each no more $300 \mathrm{MW}$ nameplate capacity) over their respective planning periods. PSCo explicitly evaluated the economics of retiring a coal plant, by constructing several candidate portfolios in which the coal plant was replaced with a new CCGT, rather than refurbishing it to extend its life. The deciding factor in the utility's decision to retire the plant was the potential carbon emission costs. Nevada Power and Sierra Pacific, in contrast, simply assumed throughout their planning analyses that plants would be retired at the end of their nominal economic lives, without explicit consideration of carbon constraints.

The carbon intensity of utilities' preferred portfolios varies widely. The gross emission rates of the fifteen utilities' preferred portfolios (again, based on only new supply- and demand-side resources in each portfolio) ranges from zero lbs/MWh to more than 1,600 lbs/MWh. Whether or not a particular utility's preferred portfolio falls in the lower half or the upper half is a function of whether or not it includes new unsequestered coal. The ten preferred portfolios containing no new coal without CCS all have composite emission rates less than $500 \mathrm{lbs} / \mathrm{MWh}$, varying largely according to the amount of new natural gas-fired generation included. Utilities with resource portfolios that include new, unsequestered coal plants have emission rates ranging from approximately 700-1,600 lbs/MWh, depending on the contribution from coal.

Aggregating the fifteen utilities' preferred portfolios provides a picture, albeit partial and provisional, of electric resource development in the Western U.S. over the next ten to twenty years. Overall, natural gas-fired generation is the largest component of the incremental energy resources in utilities' preferred portfolios, representing 33\% of the new, physical energy resources (see Figure 6). Renewables (26\%), energy efficiency (22\%), and pulverized coal without CCS (14\%) make up the lion's share of the remaining new resources, with small contributions from CHP (2\%), nuclear (1\%), IGCC with CCS (1\%), and IGCC without CCS (1\%). Overall, we see a picture of growing interest in renewable energy and energy efficiency, in part due to projected carbon regulations, but little corresponding increase in planned additions of nuclear and CCS. 


\section{Conclusions and Recommendations}

Future carbon regulations could require a dramatic shift in electric infrastructure development away from conventional fossil generation technologies, and an unprecedented scale-up of investment in low-carbon resources. Long-term resource planning can serve an instrumental role in facilitating this possible shift, by providing a framework for analyzing the potential cost and risks associated with future carbon regulations and by assessing options for mitigating that risk. For utility resource planning to serve this role effectively, however, requires confidence that the specific assumptions and methods used to analyze carbon regulatory risk are sound and will support prudent investment decisions.

Our review of recent Western utility resource plans has shown that utilities are making important strides in accounting for the financial risks associated with future carbon regulations. At the same time, their assumptions and methods vary considerably, and reveal opportunities for improvement. Energy regulators have a particularly important role in ensuring that carbon risk is appropriately addressed, given their responsibility to ensure prudent investment decisions by regulated utilities, and given that much of the costs of future carbon regulations will ultimately be born by ratepayers. State regulators and policy-makers should therefore consider providing policy guidance to utilities on appropriate assumptions and methods to be used in assessing and managing these risks in their long-term resource plans.

Though our review has focused on a subset of U.S. electric utilities, this work holds implications for all utilities and energy policymakers that are seeking to minimize the costs associated with future carbon regulations. Even in areas where carbon regulations already exist, the possibility of strengthened future policies must be considered in planning decisions. Based on our review of planning efforts in the U.S., we offer the following recommendations:

- Include a projection of carbon costs in the base-case that reflects an estimate of the mostlikely carbon regulations over the planning period.

- Evaluate candidate portfolios across a broad range of alternate carbon cost scenarios.

- Analyze a broad range of low-carbon portfolios, with well-developed cost estimates, considering all available low-carbon resource options.

- When evaluating candidate portfolio costs, account for the potentially-significant indirect impacts of future carbon regulations, including the effects on wholesale electricity market prices, natural gas prices, load growth, and coal-plant retirements.

- Effectively and clearly balance portfolio cost and risk, when selecting a preferred portfolio.

\section{Acknowledgements}

The work described in this report was funded by the Permitting, Siting and Analysis Division of the Office of Electricity Delivery and Energy Reliability of the U.S. Department of Energy under Contract No. DE-AC02-05CH11231. The study was conducted in response to a request by the Western Interstate Energy Board (an arm of the Western Governors Association). The authors would like to thank Larry Mansueti (DOE Office of Electricity Delivery and Energy Reliability) and Doug Larson (Western Interstate Energy Board) for their support of this project. For their review and helpful comments on a draft of this report, the authors would also like to thank: Mark 
Bolinger (Lawrence Berkeley National Laboratory), Phil Carver (Oregon Department of Energy), David Clement (Seattle City Light), Joe Eto (Lawrence Berkeley National Laboratory), Sy Goldstone (California Energy Commission), Corinne Grande (Seattle City Light), Lucy Johnston (Synapse Energy Economics), Clint Kalich (Avista), Brian Lanspery (Idaho Public Utilities Commission), Ron Lehr (independent consultant), Lainie Motamedi (California Public Utilities Commission), Philip Poppoff (Puget Sound Energy), David Schlissel (Synapse Energy Economics), Lisa Schwartz (Oregon Public Utilities Commission), Rich Sedano (Regulatory Assistance Project), and Garrett Voerman (Seattle City Light). Any remaining errors or omissions remain our own.

\section{References}

Andrews, C. and. S. Govil, 2007, “Becoming Proactive About Environmental Risks: Regulatory Reform and Risk Management in the US Electricity Sector,” Energy Policy, 23(10): 885-892.

Barbose, G., R. Wiser, A. Phadke, and C. Goldman, 2008, Reading the Tea Leaves: How Utilities in the West Are Managing Carbon Regulatory Risk in their Resource Plans, Lawrence Berkeley National Laboratory (forthcoming).

Bokenkamp, K, H. LaFlash, V. Singh, D. Wang, 2005, “Hedging Carbon Risk: Protecting Customers and Shareholders from the Financial Risk Associated with Carbon Dioxide Emissions.” The Electricity Journal, 18(6): 11-24.

Bolinger, M. and R. Wiser, 2005, Balancing Cost and Risk: The Treatment of Renewable Energy in Western Utility Resource Plans, Lawrence Berkeley National Laboratory, LBNL-58450.

Cavanagh, R. Gupta, A., Lashof, D. and M. Tatsutani, 1993, "Utilities and $\mathrm{CO}_{2}$ emissions: Who Bears the Risks of Future Regulation?” The Electricity Journal, 6(2): 64-75.

Clemmer, S. and B. Freese, 2006, Gambling with Coal: How Future Climate Laws Will Make New Coal Power Plants More Expensive,” Cambridge, Massachusetts: Union of Concerned Scientists.

Gardiner and Associates, 2006, Best Practices in Climate Change Risk Analysis for the Electric Power Sector,” A Ceres Report, Boston, Massachusetts: Ceres.

GF Energy, 2007, 2007 Electricity Outlook.

EIA, 2003, Analysis of S. 139, the Climate Stewardship Act of 2003, Energy Information Administration, SR/OIAF/2003-02.

EIA, 2007a, Energy Market and Economic Impacts of a Proposal to Reduce Greenhouse Gas Intensity with a Cap and Trade System, Energy Information Administration, SR/OIAF/200701. 
EIA, 2007b, Energy Market and Economic Impacts of S. 280, the Climate Stewardship and Innovation Act of 2007, Energy Information Administration, SR/OIAF/2007-04.

EIA, 2007c, Supplement to Energy Market and Economic Impacts of S.280, Energy Information Administration.

Hopper, N., C. Goldman, and J. Schlegel, 2006, Energy Efficiency in Western Utility Resource Plans: Impacts on Regional Resource Assessment and Support for WGA Policies, Lawrence Berkeley National Laboratory, LBNL-58271.

Johnston, L., E. Hausman, A. Sommer, B. Biewald, T. Woolf, D. Schlissel, A. Roschelle, and D. White, 2006, Climate Change and Power: Carbon Dioxide Emissions Costs and Electricity Resource Planning, Synapse Energy Economics.

Lempert, R.J., D. Groves, S. Popper, and S.C. Bankes, 2006, “A General Method for Generating Robust Strategies and Narrative Scenarios,” Management Science, April 2006.

Lutsey and D. Sperling, 2008, “America's bottom-up climate change mitigation policy,” Energy Policy, (36)2: 637-685.

Markowitz, H., 1952, “Portfolio Selection,” Journal of Finance, 7(1), 77-91.

National Action Plan for Energy Efficiency, 2007, Guide for Conducting Energy Efficiency Potential Studies, prepared by Optimal Energy, Inc. August.

NCEP, 2004, Ending the Energy Stalemate: A Bipartisan Strategy to Meet America's Energy Challenges, The National Commission on Energy Policy.

Parry, I.W.H. and W.A. Pizer, 2007, "Emissions Trading vs. $\mathrm{CO}_{2}$ Taxes vs. Standards," in Assessing U.S. Climate Policy Options: A report summarizing work at RFF as part of the inter-industry U.S. Climate Policy Forum, R.J. Kopp and W.A. Pizer (eds.), Resources for the Future.

Pew Center, 2006, Climate Change 101: State Action, Pew Center on Global Climate Change, http://www.pewclimate.org/docUploads/101_States.pdf

Pew Center, 2006, Learning from State Action on Climate Change: March 2007 Update, Pew Center on Global Climate Change, http://www.pewclimate.org/docUploads/States\%20Brief\%20Template\%20_March\%202007 igph.pdf.

Repetto, R. and J. Henderson, 2003, "Environmental Exposures in the US Electric Utility Industry.," Utilities Policy, 11: 103-111.

Rufo, M. and F. Coito, 2002, California's Secret Energy Surplus: The Potential for Energy Efficiency, prepared for the Energy and Hewlett Foundations, September 23. 
WCI, 2007, Western Climate Initiative Statement of Regional Goal, Western Climate Initiative, http://www.westernclimateinitiative.org/ewebeditpro/items/O104F13012.pdf.

Wiser, R., Bachrach, D., Bolinger, M., and W. Golove, 2004, “Comparing the Risk Profiles of Renewable and Natural Gas-Fired Electricity Contracts,” Renewable and Sustainable Energy Reviews, 8: 335-363.

Wiser, R., M. Bolinger, M. St. Clair, 2005, Easing the Natural Gas Crisis: Reducing Natural Gas Prices Through Increased Deployment of Renewable Energy and Energy Efficiency, Lawrence Berkeley National Laboratory, LBNL-56756. 
Table 1. Utility Resource Plans Included in This Study

\begin{tabular}{|c|c|c|c|}
\hline Utility & Service Territory & $\begin{array}{c}\text { Year of } \\
\text { Resource } \\
\text { Plan } \\
\end{array}$ & $\begin{array}{c}\text { Portfolio } \\
\text { Construction } \\
\text { Period* }^{*} \\
\end{array}$ \\
\hline Avista & Idaho, Washington & 2007 & $2008-2027$ \\
\hline Idaho Power & Idaho, Oregon & 2006 & $2006-2025$ \\
\hline Los Angeles Department of Water and Power (LADWP) & California & 2006 & $2006-2025$ \\
\hline Nevada Power & Nevada & 2006 & $2007-2026$ \\
\hline NorthWestern & Montana & 2007 & $2008-2027$ \\
\hline PacifiCorp & $\begin{array}{c}\text { Oregon, Utah, } \\
\text { Wyoming, Washington, } \\
\text { Idaho, California }\end{array}$ & 2007 & 2007-2016 \\
\hline Pacific Gas \& Electric (PG\&E) & California & 2006 & $2007-2016$ \\
\hline Portland General Electric (PGE) & Oregon & 2007 & 2008-2012 \\
\hline Public Service Company of Colorado/Xcel (PSCo) & Colorado & 2007 & $2008-2020$ \\
\hline Puget Sound Energy (PSE) & Washington & 2007 & $2008-2027$ \\
\hline Southern California Edison (SCE) & California & 2006 & $2007-2016$ \\
\hline San Diego Gas \& Electric (SDG\&E) & California & 2006 & $2007-2016$ \\
\hline Seattle City Light & Washington & 2006 & $2007-2026$ \\
\hline Sierra Pacific & Nevada, California & 2007 & $2008-2027$ \\
\hline Tri-State Generation and Transmission & $\begin{array}{c}\text { Colorado, New Mexico, } \\
\text { Wyoming, Nebraska }\end{array}$ & 2007 & $2007-2025$ \\
\hline
\end{tabular}

* The portfolio construction period is the time horizon over which each utility identified all elements of its candidate resource portfolios. 
Table 2. Indirect Carbon Regulation Impacts Accounted for in Resource Planning Analysis

\begin{tabular}{|c|c|c|c|c|c|c|c|c|c|}
\hline Utility & 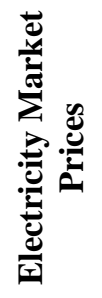 & 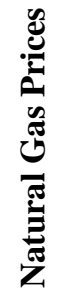 & 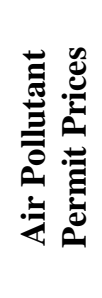 & 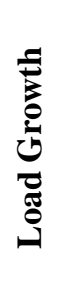 & 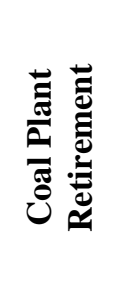 & 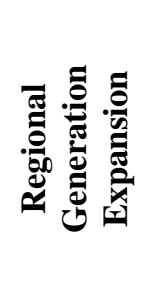 & 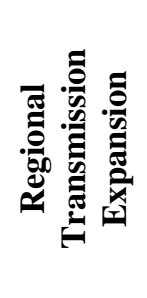 & 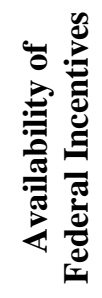 & 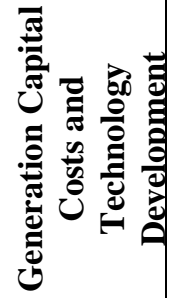 \\
\hline Avista & $\checkmark$ & & & $\checkmark$ & & $\checkmark$ & & $\checkmark$ & \\
\hline Idaho Power & $\checkmark$ & & & & & & & & \\
\hline \multicolumn{10}{|l|}{ LADWP } \\
\hline Nevada Power & & & $\checkmark$ & & & & & & \\
\hline NorthWestern & $\checkmark$ & & & & & & & & \\
\hline PacifiCorp & $\checkmark$ & $\checkmark$ & $\checkmark$ & & & $\checkmark$ & & & \\
\hline PG\&E & $*$ & & & & & & & & \\
\hline PGE & $\checkmark$ & & & & $\checkmark$ & & & & \\
\hline PSCo & $\checkmark$ & $\checkmark$ & & $\checkmark$ & $\checkmark$ & & & & \\
\hline PSE & $\checkmark$ & $\checkmark$ & & $\checkmark$ & & $\checkmark$ & & & \\
\hline SCE & $*$ & & & & & & & & \\
\hline SDG\&E & $*$ & & & & & & & & \\
\hline Seattle City Light & $\checkmark$ & $\checkmark$ & & $\checkmark$ & & $\checkmark$ & & & \\
\hline Sierra Pacific & & & $\checkmark$ & & & & & & \\
\hline Tri-State G\&T & & & & & & & & & \\
\hline
\end{tabular}

Note: The absence of a check mark $(\checkmark)$ indicates either that the utility did not account for a particular impact or that its resource plan did not provide sufficient detail to determine whether or not it accounted for that impact. The asterisks (*) shown for PG\&E, SCE, and SDG\&E indicate that these utilities did not account for carbon regulations in their electricity price forecast, but they did include their base-case carbon price as an adder when evaluating the cost effectiveness of energy efficiency and renewable energy resource acquisitions. 


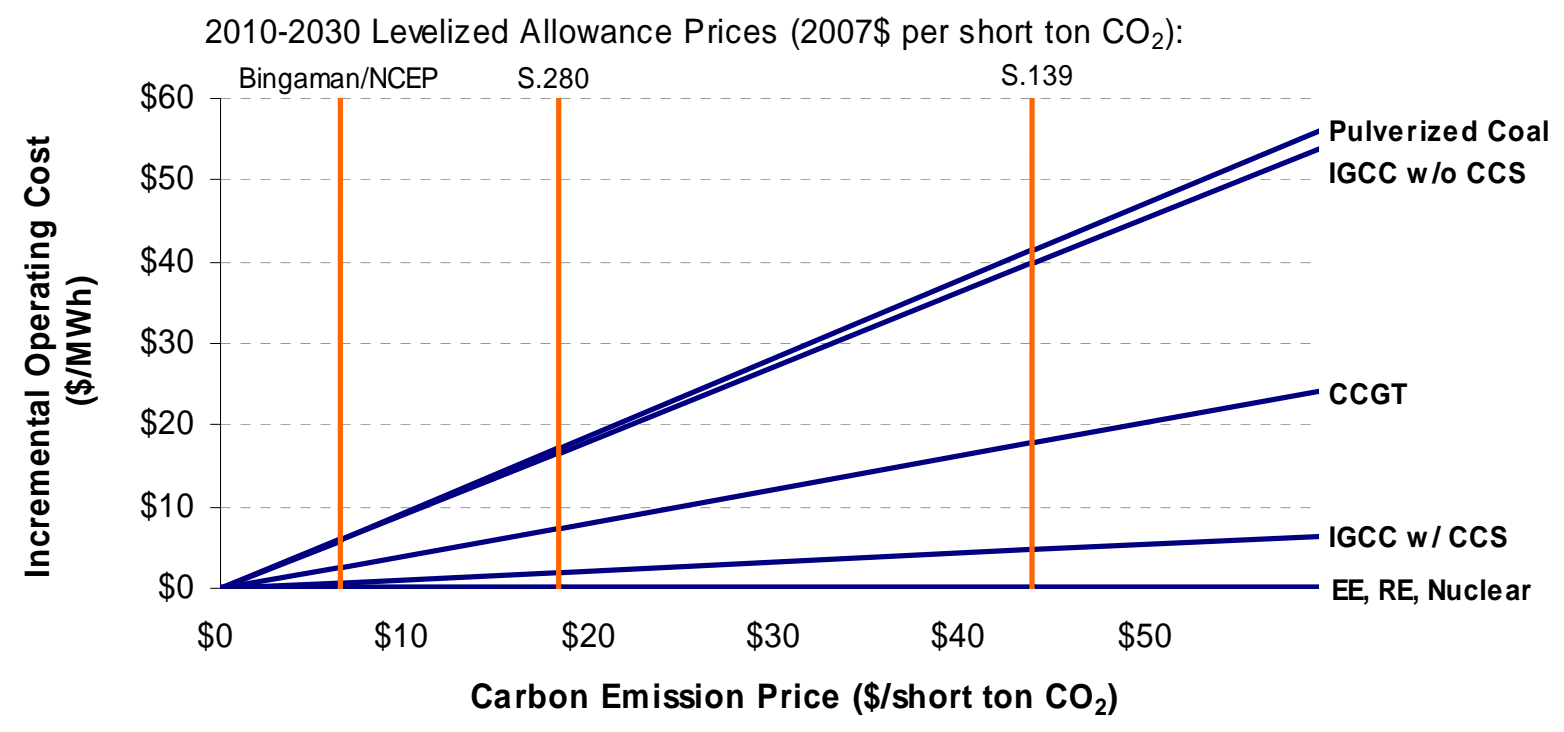

Figure 1. The Effect of Carbon Regulations on the Operating Cost of Different Resources 


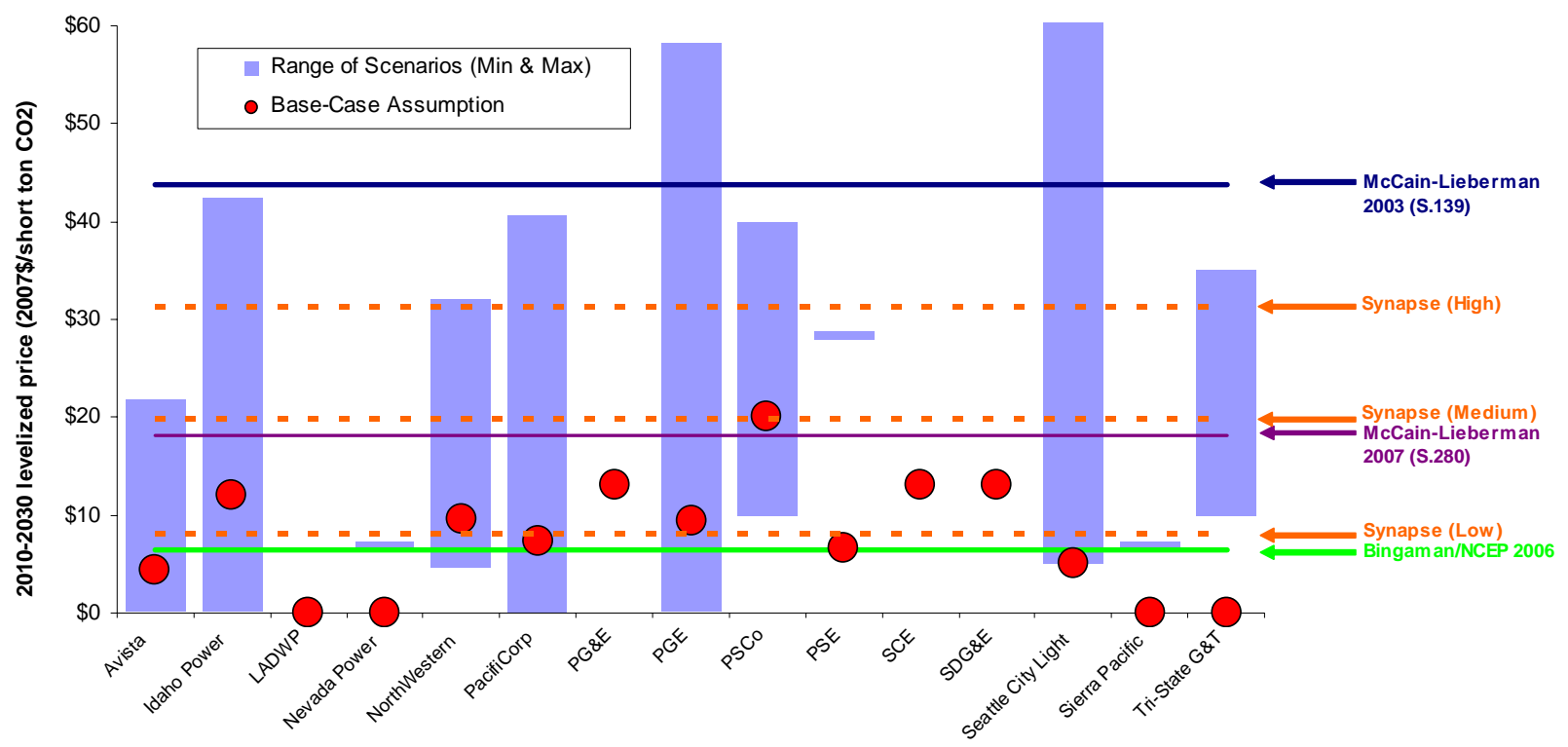

Figure 2. Levelized $\mathrm{CO}_{2}$ Emission Prices Used in Utility Resource Plans (2010-2030) 


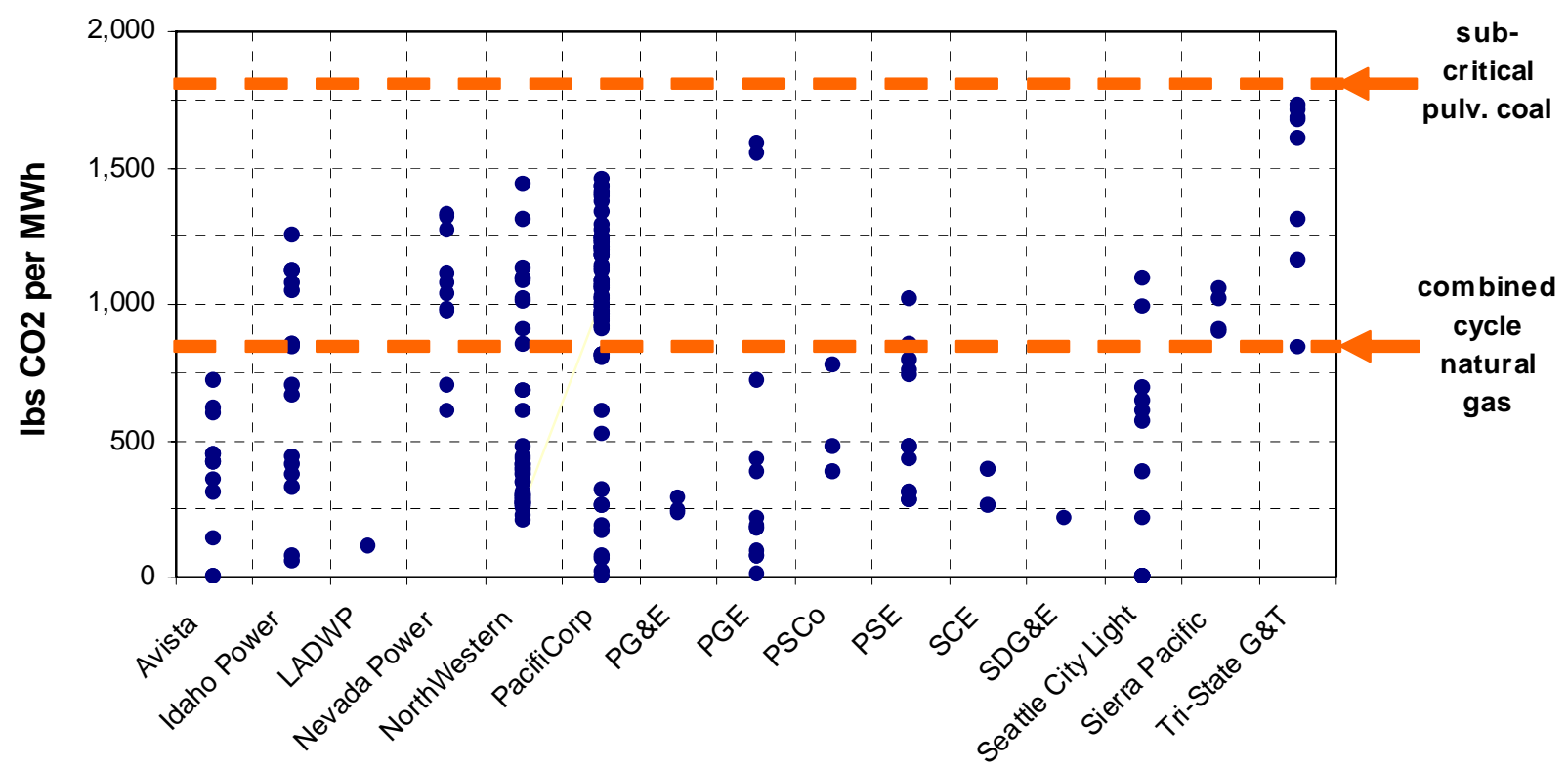

Figure 3. Composite $\mathrm{CO}_{2}$ Emission Rates of Candidate Portfolios (New Resources)

Notes: Avista and Seattle City Light both evaluated multiple zero-carbon candidate portfolios, which are superimposed upon one another in the figure. Also, Avista and PSCo constructed a larger number of candidate portfolios than shown in the figure, but only identified the composition of the sub-set of candidate portfolios depicted in the figure. 


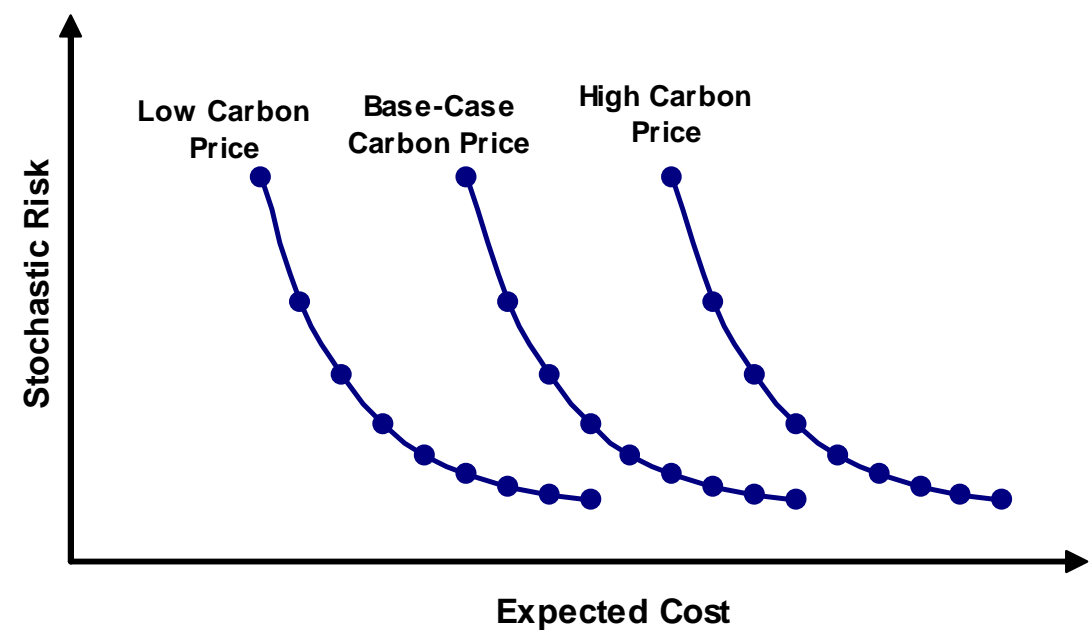

Figure 4. Efficient Frontier of Candidate Portfolios for Multiple Carbon Price Scenarios 


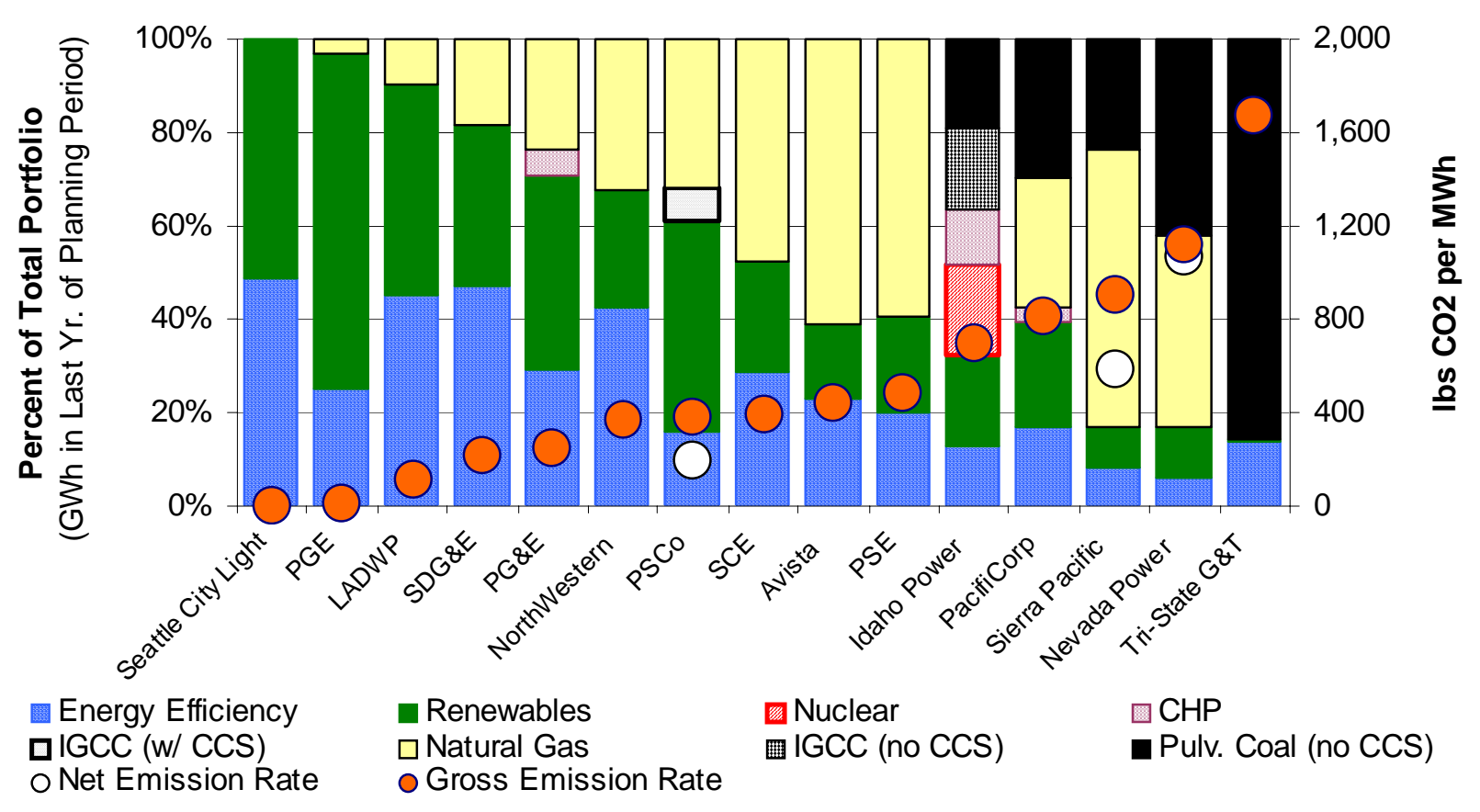

Figure 5. New Resources in Utilities' Preferred Portfolios 


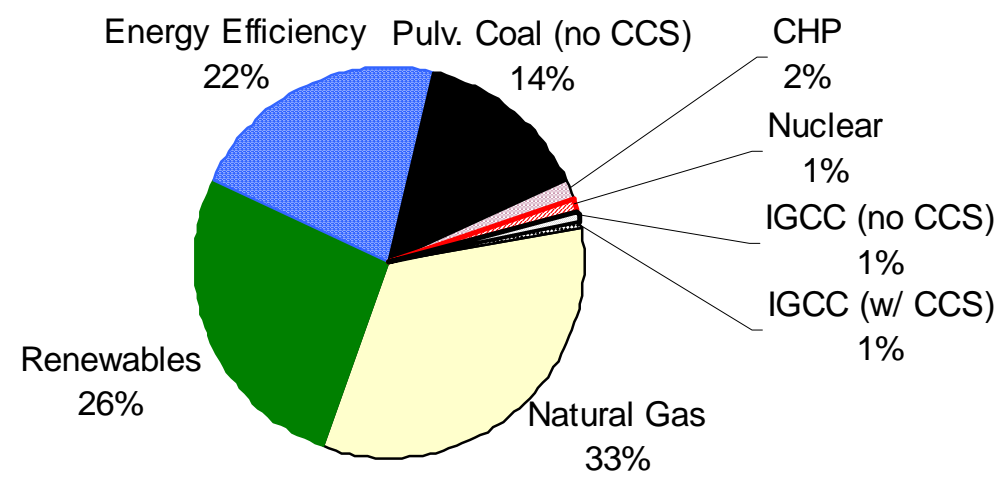

Figure 6. Aggregate Composition of Western Utilities’ Preferred Resource Portfolios 